\title{
Feto-maternal outcome in twin pregnancy
}

\section{Amiben V. Gajera ${ }^{1}$, Hiremath P. Basavannayya ${ }^{1} *$, C. Kavitha $^{1}$, Reshma Hiremath ${ }^{2}$}

\author{
${ }^{1}$ Department of Obstetrics \& Gynaecology, SVMCH\&RC Ariyur, Pondicherry, India \\ ${ }^{2}$ IMO Mapuca, Goa, India
}

Received: 25 September 2015

Accepted: 30 October 2015

\section{*Correspondence:}

Dr. Hiremath P. Basavannayya,

E-mail: Hiremath0312@gmail.com

Copyright: (c) the author(s), publisher and licensee Medip Academy. This is an open-access article distributed under the terms of the Creative Commons Attribution Non-Commercial License, which permits unrestricted non-commercial use, distribution, and reproduction in any medium, provided the original work is properly cited.

\begin{abstract}
Background: Natural higher orders multiple conceptions are uncommon. The reported incidence ranges from $0.01 \%$ to $0.07 \%$ of all pregnancies. Multiple births are much more common today than they were in the past. Throughout the world, the prevalence of twin births varies from approximately 2-20/1000 birth. Overall complications occur in approximately $83 \%$ of twin pregnancies as compared to $25 \%$ in singleton pregnancies. This delayed childbearing has resulted in an increased maternal age at conception.

Methods: Present study is a randomized prospective study of 100 cases of twin pregnancies admitted at our institute from July, 2009 to October, 2011 including all emergency as well as registered cases. . Patients included in this study were from various socio-economic classes and they were having a different level of education. In all cases a detailed history was taken, all routine and specific investigations were done.

Results: In this prospective study we observed 100 cases of twin pregnancies. In this study most of the patients (46\%) delivered at 33- 36 weeks of gestation. 5\% of patients had abortion at an early gestation. Majority of the patients delivered vaginally (61\%), followed by LSCS (Lower Segment Caesarean Section) (38\%). In this study low birth weight babies were the most common (188 babies) to the extent of $94 \%$. We had $11 \%$ (22) extremely low birth weight babies. There were 13 neonatal deaths $(6.5 \%)$. We observed the highest incidence of twins in the age group of $20-29$ years. The least were below the age of 20 years. The incidence among primigravida and multigravida was almost the same.

Conclusions: Most of the complications in multiple gestations are preventable. High risk units in the obstetric ward and well developed NICU set up would reduce the maternal, perinatal morbidity and mortality.
\end{abstract}

Keywords: Twins, Ovulation induction, Preterm, Low birth weight baby, Perinatal morbidity. Perinatal mortality

\section{INTRODUCTION}

Twin pregnancies have occupied a very prominent place in human mythology since ancient times. Hindu mythology enshrined the twins Luv \& Kush, sons of Lord Rama; ancient Rome was said to have been founded by the twins Ramus \& Romulus.

Natural higher order multiple conceptions are uncommon. The reported incidence ranges from $0.01 \%$ to $0.07 \%$ of all pregnancies. ${ }^{1}$ Multiple births are much more common today than they were in the past. Throughout the world, the prevalence of twin births varies from approximately 2-20/1000 births. Multiple pregnancy warrants a special attention because they make a considerable contribution to the maternal / perinatal morbidity/mortality well in excess of that due to multiplication of singleton risk by fetal number. ${ }^{2,3}$ Overall complications occur in approximately $83 \%$ of twin pregnancies as compared to $25 \%$ in singleton pregnancies. Hence twin pregnancies should be considered as high risk pregnancies. Vigilant obstetric care not only decreases the maternal morbidity and mortality but also improves the fetal outcome. 
The astounding increase in multiple gestation rates can be explained by the social shift in women's attitude regarding child bearing which has resulted in more and more women choosing to postpone child bearing in favour of work and career commitments. This delayed childbearing has resulted in an increased maternal age at conception, which in turn has led to infertility treatment such as ovulation induction, in vitro fertilization and intra cytoplasmic sperm injection as one of the predisposing factors of twin gestation, since fertility decreases with age. $^{4,5}$

The aim and objectives of the study was to study the epidemiology, maternal fetal complications and to analyse perinatal morbidity and mortality associated with twin gestation in our institute during July, 2009 to October 2011 and to emphasize the role of regular antenatal check up to improve the maternal and perinatal outcome in twin pregnancies.

\section{METHODS}

Present study is a randomized prospective study of 100 cases of twin pregnancies admitted at our institute from July, 2009 to October, 2011 including all emergency as well as registered cases. This study was conducted as a part of post-graduate dissertation at Smt. NHL Municipal Medical College, Ahmadabad, India. Patients included in this study were from various socio-economic classes and they were having a different level of education. In all cases a detailed history was taken, all routine and specific investigations were done. Hospitalization was done whenever it was required to prevent and to treat complications. All these patients were delivered in our institute under close observation. All stages of labour were carefully managed in the presence of team of obstetrician. All babies were examined by the neonatologist and NICU care was given as and when it was required.

\section{RESULTS}

In this prospective study we observed 100 cases of twin pregnancies. Triplets and quadruplets were not included as the numbers were small. We had an incidence of twin pregnancy to the extent of 17.6/1000 live births. Out of the 100 twin pregnancies 70 patients were booked in our hospital, 30 patients were unbooked and had got admitted with some complications.

We noticed that the incidence of twin pregnancy was highest in the age group of 20-24 years followed by 25 29 years which were $51 \%$ and $29 \%$ respectively. The least incidence was seen in patients above 35 years which was around $2 \%$.As for the incidence of twin pregnancy with regards to the parity, we came across the highest incidence in primi gravida, the least was being in multi para with parity more than 3 (Table 1 ).
Table 1: Demographic and gestation at delivery.

\begin{tabular}{|c|c|c|c|c|}
\hline $\begin{array}{l}\text { Demographic } \\
\text { \& Obstetric } \\
\text { features }\end{array}$ & Number & Percentage & Mean & SD \\
\hline \multicolumn{5}{|l|}{ Age (years) } \\
\hline$<20$ & 5 & 4.0 & - & - \\
\hline $20-29$ & 80 & 60.0 & - & - \\
\hline $30-35$ & 15 & 36.0 & - & - \\
\hline \multicolumn{5}{|l|}{ Parity } \\
\hline Primipara & 49 & 34.0 & - & - \\
\hline Multipara & 51 & 66.0 & - & - \\
\hline \multicolumn{5}{|c|}{ Weeks of Gestation at delivery } \\
\hline$<28$ & 10 & & - & - \\
\hline $29-32$ & 18 & & - & - \\
\hline $33-36$ & 46 & & - & - \\
\hline $37-42$ & 26 & & - & - \\
\hline Height (cm) & - & - & 152.3 & 6.2 \\
\hline Weight (kg) & - & - & 64.3 & 9.8 \\
\hline
\end{tabular}

In the present study we noticed that maximum twin pregnancies were a result of spontaneous conception which was $75 \%$ followed by conceptions from ovulation induction (Table 2). Three patients gave positive family history of twins, however only one patient gave past history of the same. None of them had a paternal history or recent use of oral contraceptive pills.

Table 2: Influence on ovulation induction \& heredity on twin gestation.

\begin{tabular}{|lll|}
\hline History & Cases & Percentage \% \\
\hline Spontaneous & 75 & 75 \\
\hline Ovulation Induction & 25 & 25 \\
\hline Maternal History & 03 & 3 \\
\hline Past History & 1 & 1 \\
\hline Paternal History & 0 & 0 \\
\hline H/o OCP & 0 & 0 \\
\hline *Oral Contraceptive Pill & &
\end{tabular}

Table 3: Distribution of patients by fetal presentation.

\begin{tabular}{|lll|}
\hline Presentation & Number & Percentage \% \\
\hline Vertex-Vertex & 60 & 60 \\
\hline Vertex-Breech & 23 & 23 \\
\hline Vertex-Transverse & 2 & 2 \\
\hline Breech-Vertex & 1 & 1 \\
\hline Breech-Breech & 7 & 7 \\
\hline Breech-Transverse & 1 & 1 \\
\hline Both Transverse & 2 & 2 \\
\hline Abortion & 5 & 5 \\
\hline
\end{tabular}

In this study most of the patients (46\%) delivered at 3336 weeks of gestation. $5 \%$ of patients had abortion at an early gestation. Six women delivered at or before 24 weeks of gestation and only $26 \%$ had completed 37 weeks. We came across vertex-vertex as the most 
common presentation $(60 \%)$ followed by vertex- breech presentation (25\%), least was either vertex - transverse or breech - transverse (Table 3). Majority of the patients delivered vaginally $(61 \%)$, followed by LSCS (Lower Segment Caesarean Section) (38\%). There was no incidence of internal podalic version (Table 4). However we had one case in which the first twin was delivered vaginally and second twin had to be delivered by LSCS (Lower Segment Caesarean Section), as the patient had cord prolapse with very high presenting part. In majority of the cases indication for the LSCS was unfavourable presentation.

Table 4: Distribution of patients by their mode of delivery.

\begin{tabular}{|lcl|}
\hline Mode of Delivery & No. of Patients & Percentage \\
\hline Vaginal Delivery & 56 & 56 \\
\hline LSCS & 39 & 39 \\
\hline
\end{tabular}

Table 5: Complications encountered by the mothers.

\begin{tabular}{|c|c|}
\hline Complication & Number \\
\hline Anemia & 7 \\
\hline $\begin{array}{l}\text { Hypertension(PIH \& Pre- } \\
\text { eclampsia) }\end{array}$ & 24 \\
\hline Polyhydramnios & 6 \\
\hline Postpartum Hemorrhage & 3 \\
\hline Ante partum Hemorrhage & 1 \\
\hline $\begin{array}{l}\text { Preterm } \\
\text { Labor(Spontaneous/Induced) }\end{array}$ & 69 \\
\hline Gestational Diabetes & 1 \\
\hline Abortion & 5 \\
\hline Eclampsia & 1 \\
\hline Oligohydramnios & 3 \\
\hline No Complication & 16 \\
\hline
\end{tabular}

Table 6: Perinatal neonatal complications.

\begin{tabular}{|lcc|}
\hline Premature Babies & Cases & Percentage \% \\
\hline $\mathrm{Wt}<1500 \mathrm{gm}$ & 138 & 69 \\
\hline $\mathrm{Wt}<1500-2000 \mathrm{gm}$ & 58 & 28.4 \\
\hline $\mathrm{Wt}<2000-2500 \mathrm{gm}$ & 49 & 29.6 \\
\hline $\mathrm{Wt}>2500 \mathrm{gm}$ & 22 & 28.9 \\
\hline Both IUD & 12 & 13 \\
\hline Single Fetus Death & 9 & 4.5 \\
\hline Fetus Compression & 1 & 0.5 \\
\hline NICU Admissions & 53 & 26.5 \\
\hline Neonatal Death & 13 & 6.5 \\
\hline Foot Deformities & 2 & 1 \\
\hline
\end{tabular}

As for the maternal complications in twin pregnancies, we encountered preterm labour either spontaneous or induced/threatened preterm labour in 69 women. We noticed pre eclampsia among 24 women. However, only one patient had eclampsia. Severe anaemia was noticed in 7 women, which was treated by blood transfusion, $5 \%$ had abortion, 1 patient had gestational diabetes and there were 3 patients with severe oligohydramnios (Table 5).

The study revealed that the twins born were mostly low birth weight babies (188 babies) to the extent of $94 \%$. We had $11 \%$ (22) extremely low birth weight babies. There were 13 neonatal deaths $(6.5 \%)$, single fetus demise in 9 $(4.5 \%)$ and a single case of fetus compresses (Table No: 6). Two cases of foot deformity were also noticed.

\section{DISCUSSION}

Traditionally multiple pregnancies are regarded to be unfavourable, probably due to the poor perinatal outcome, increased maternal mortality and morbidity, long term developmental issues and the expensive treatment involved. In the present study, we considered only twin pregnancies, the incidence of which was 17.6/1000 births. According to various studies conducted since the 1970s, the maternal twinning rate in India on an average is $9-16 / 1000$ births. $^{6}$ The main contributing factor for the twin rate in this study seems to be the referral of all high risk cases to our hospital, it being a tertiary care centre.

The patients who conceived by ovulation induction or by in vitro fertilization belonged to higher socio-economic status and could afford expensive medical treatment in private sectors. This could be the reason that the number of patients with spontaneous twinning was higher in our government setup compared to the ovulation induction. However, $25 \%$ of the twins were as result of ovulation induction. As a matter of fact all were induced by Clomiphene Citrate by the local practitioners. These were the patients who belong to lower socio-economic condition and had been registered in our setup.

We observed the highest incidence of twins in the age group of 20-29 years. The least were below the age of 20 years. The incidence among primigravidae and multigravidae was almost the same. Our observation of the twin pregnancies showed that the majority of them were registered, had regular check-up, took adequate ultrasounds and was compliant to all the advice given to them. Inspite of good ante-natal care, $46 \%$ of the women delivered before 36 weeks of gestation, $10 \%$ delivered before 28 weeks and $18 \%$ delivered at $29-32$ weeks of gestation. The incidence of preterm delivery was higher (74\%) in the current study as compared to Chowdhury et al (44\%).However, the incidence reported by Bangal et al was much higher $(88 \%)^{7,8}$

In this study the incidence of anaemia was $7 \%$, Spellacy et al found anaemia in $9.4 \%$ and Chowdhury et al in $26 \%$ of twin pregnancies. There is a considerable improvement in the prenatal care in India which is evidenced by a much lesser incidence of anaemia than it was in the past ${ }^{9}$. Hypertension (Pregnancy Induced Hypertension, Pre eclampsia) was seen in $24 \%$ which was high compared to that of the Spellacy et al study (12.9\%). Post-partum 
hemorrhage (PPH) occurred in 3\% which is comparable to the incidence of PPH in developed countries; this improvement in the PPH incidence is seen in India after the introduction of newer prostaglandins.

Other complications which we came across were polyhydramnios $(6 \%)$, oligohydramnios $(3 \%)$ and $\mathrm{APH}$ (Ante partum Hemorrhage) (1\%). No complications were seen in $16 \%$ of cases. The commonest presentation was vertex-vertex and the commonest mode of delivery was normal delivery. The study conducted by Chittacharoen showed that caesarean section was the commonest mode of delivery. ${ }^{10,11}$

There was no maternal mortality in our study. More than half of the babies were delivered preterm, which was higher than Hashimoto et al and other series (29\%$54 \%)^{10}$. This higher incidence could be due to a higher rate of preterm termination, as we had $24 \%$ of preeclampsia patients and $6 \%$ of both twin IUD. There was also a significant number of unregistered cases. The incidence of having a baby with low birth weight (of less than 2500 gms) was 86.9\%; however, Bangal et al showed an incidence of $82 \%$. In the present study perinatal mortality in the form of neonatal deaths and intrauterine deaths was $17 \%$. Sulthan et al reported a perinatal mortality of $11 \%$. Perinatal morbidity which required admission in neonatal unit was $26.5 \%$. Majority of these babies were preterm babies and had complications like IUGR, birth asphyxia and septicaemia.

\section{CONCLUSIONS}

Most of the complications in multiple gestations are preventable. High risk units in the obstetric ward and well developed NICU set up would reduce the maternal, perinatal morbidity and mortality.

Funding: No funding sources Conflict of interest: None declared

Ethical approval: The study was approved by the Institutional Ethics Committee

\section{REFERENCES}

1. Umeora OUJ, AneziOkoro EA, Egwuatu VE. Higher-order multiple births in Abakaliki, Southeast Nigeria. Singapore. Med J. 2011;52(3):163-7.

2. Conde-Agudelo A, Belizan JM, Lindmark G. Maternal morbidity and mortality associated with multiple gestation. Obstet Gynecol. 2000;95:899904.

3. Yasmeen N, Aleem M, Iqbal N. Maternal and fetal complications in multiple pregnancies. Ann $\mathrm{K} \mathrm{Ed}$ Med Coll. 2006;12:512-4.

4. Blondel B, Kaminski M. Trends in the occurrence, determinants, and consequences of multiple births. Semin Perinatol. 2002;26:239-49.

5. Jewell SE, Yip R. Increasing trends in plural births in the United States. Obstet Gynecol. 1995;85:229-32.

6. Little J, Thompson B. Descriptive epidemiology. In: McGillivray I, Campbell DM, Thompson BJ, editors. Twinning and Twins. New York: Wiley. 1988;37-66.

7. Chowdhury S, Hussain MA. Maternal complications in twin pregnancies. Mymensingh Med J. 2011;20(1):83-7.

8. Vidyadhar B. Bangal, Shruti M Patel, Devendra N Khairnar. Study of maternal and fetal outcome in twin gestation at tertiary care teaching hospital. IJBAR. 2012;03(10):758-61.

9. Spellacy WN, Handler A, Ferre CD. A case control study of 1253 twin pregnancies from $1982-1987$. Perinatal database. 1990;75:198-71.

10. Chittacharoen A. Pregnancy outcome of twin pregnancy in Ramathibodi Hospital. J Med Assoc Thai. 2006;89:576-80.

11. Obstetric and Perinatal Outcome of Multiple Pregnancy Gulrukh Qazi. Journal of the College of Physicians and Surgeons Pakistan. 2011;21(3):142-5.

Cite this article as: Gajera AV, Basavannayya HP, Kavitha C, Hiremath R. Feto-maternal outcome in twin pregnancy. Int J Reprod Contracept Obstet Gynecol 2015;4:1836-9. 